\title{
Recombinant Macrophage Inflammatory Protein-2 Beta
}

National Cancer Institute

\section{Source}

National Cancer Institute. Recombinant Macrophage Inflammatory Protein-2 Beta. NCI

Thesaurus. Code C2560.

A formulated therapeutic analog of the endogenous pro-inflammatory alpha (CXC)

chemokine macrophage inflammatory protein-2 beta that stimulates neutrophil

chemotaxis and induces neutrophil degranulation. ( $\mathrm{NCI04)}$ 